\title{
Collagen-based silver nanoparticles: Study on cell viability, skin permeation, and swelling inhibition
}

\author{
Vinicius Saura Cardoso ${ }^{\mathrm{a}, \mathrm{b}, *}$, Marcelo de Carvalho Filgueiras ${ }^{\mathrm{b}, \mathrm{c}}$, Yago Medeiros Dutra ${ }^{\mathrm{b}, \mathrm{c}}$, \\ Ramon Handerson Gomes Teles b,c, Alyne Rodrigues de Araújo a, Fernando Lucas Primo d, Ana Carolina Mafud e, \\ Larissa Fernandes Batista ${ }^{e}$, Yvonne Primerano Mascarenhas e , Iêda Maria Martinez Paino ${ }^{\mathrm{f}}$, Valtencir Zucolotto ${ }^{\mathrm{f}}$, \\ Antonio Claudio Tedesco ${ }^{\mathrm{g}}$, Durcilene Alves Silva ${ }^{a}$, José Roberto S.A. Leite ${ }^{\mathrm{a}, \mathrm{h}}$, José Ribeiro dos Santos Jr. ${ }^{\mathrm{i}}$ \\ a Research Center in Biodiversity and Biotechnology, Biotec, Campus Ministro Reis Velloso, Federal University of Piauí, UFPI, 64202020 Parnaíba, Piauí, Brazil \\ b Physiotherapy Department, Campus Ministro Reis Velloso, Federal University of Piauí, UFPI, 64202020 Parnaíba, Piauí, Brazil \\ c Morphology and Muscle Physiology Laboratory, LAMFIM, Campus Ministro Reis Velloso, Federal University of Piaú, UFPI, 64202020 Parnaíba, Piauí, Brazil \\ d Faculdade de Ciências Farmacêuticas, UNESP, Universidade Estadual Paulista, Campus de Araraquara, Departamento de Bioprocessos e Biotecnologia, 14800903 Araraquara, São Paulo, Brazil \\ e Institute of Physics of São Carlos, IFSC, University of São Paulo, USP, 13566590 São Carlos, SP, Brazil \\ ${ }^{\mathrm{f}}$ Nanomedicine and Nanotoxicology Group, Institute of Physics of São Carlos, IFSC, University of São Paulo, USP, 13566-590 São Carlos, SP, Brazil \\ ${ }^{g}$ Departamento de Química, Laboratório de Fotobiologia e Fotomedicina, Faculdade de Filosofia, Ciências e Letras de Ribeirão Preto, Universidade de São Paulo, USP, 14040901 Ribeirão Preto, SP, Brazil \\ h Área de Morfologia, Faculdade de Medicina, FM, Universidade de Braśilia, UnB, Campus Universitário Darcy Ribeiro, Brasília, 70910900, Distrito Federal, Brazil \\ i Department of Chemistry, Campus Teresina, Federal University of Piauí, 64049-550 Teresina, Piauí, Brazil
}

\section{A R T I C L E I N F O}

\section{Article history:}

Received 2 August 2016

Received in revised form 24 November 2016

Accepted 4 December 2016

Available online 7 December 2016

\section{Keywords:}

Nanoparticle

Silver

Collagen

Nanotoxicology

MV3 cancer cell

L929 fibroblast cell

\begin{abstract}
A B S T R A C T
Collagen is considered the most abundant protein in the animal kingdom, comprising $30 \%$ of the total amount of proteins and $6 \%$ of the human body by weight. Studies that examine the interaction between silver nanoparticles and proteins have been highlighted in the literature in order to understand the stability of the nanoparticle system, the effects observed in biological systems, and the appearance of new chemical pharmaceutical products. The objective of this study was to analyze the behavior of silver nanoparticles stabilized with collagen (AgNPcol) and to check the skin permeation capacity and action in paw edema induced by carrageenan. AgNPcol synthesis was carried out using solutions of reducing agent sodium borohydride $\left(\mathrm{NaBH}_{4}\right)$, silver nitrate $\left(\mathrm{AgNO}_{3}\right)$ and collagen. Characterization was done by using dynamic light scattering (DLS) and X-ray diffraction (XRD) and AFM. Cellular viability testing was performed by using flow cytometry in human melanoma cancer (MV3) and murine fibroblast (L929) cells. The skin permeation study was conducted using a Franz diffusion cell, and the efficiency of AgNPcol against the formation of paw edema in mice was evaluated. The hydrodynamic diameter and zeta potential of AgNPcol were $140.7 \pm 7.8 \mathrm{~nm}$ and $20.1 \pm 0.7 \mathrm{mV}$, respectively. AgNPcol failed to induce early apoptosis, late apoptosis, and necrosis in L929 cells; however, it exhibited enhanced toxicity in cancer cells (MV3) compared to normal cells (L929). AgNPcol demonstrated increased toxicological effects in cancer MV3 cells, promoting skin permeation, and preventing paw edema.
\end{abstract}

(C) 2016 Elsevier B.V. All rights reserved.

\section{Introduction}

Collagen is a fibrous protein found in skin, tendons, bones, teeth, blood vessels, intestines, and cartilage, comprising $30 \%$ of the total amount of proteins and $6 \%$ of the human body by weight [1]. Thus, it is considered the most abundant protein in the animal kingdom $[2,3]$ and has various functions in the body that range from supporting organs and tissues to storing energy [4].

\footnotetext{
* Corresponding author at: Campus Ministro Reis Velloso, Federal University of Piauí, UFPI, 64202020 Parnaíba, Piauí, Brazil.

E-mail address: vscfisio@ufpi.edu.br (V.S. Cardoso).
}

There is growing interest in the use of collagen owing to its diverse properties. Collagen has low allergenicity, low antigenicity, and high biocompatibility [5]. It is bioabsorbable, hemostatic [6,7], biodegradable, non-toxic [3], synergistic with bioactive components, and compatible with natural and synthetic polymers [6]. Additionally, it possesses high tensile strength and exhibits high affinity for water $[6,8]$.

Until the 1980s, the importance of collagen as a biomaterial was restricted to the production of surgical sutures. Currently, its applications range from coating large caliber vascular prosthesis to supporting the orientation of growing nerve cells. The increase in the application of collagen as a biomaterial is due to its natural abundance [4] and the diversity of ways by which it can be molded [6,7]. 
In the 1990s, up to 26 types of collagen were identified owing to the complexity and diversity in structure, additional presence of non-helical domains, structure of assembly, and function of collagen. Collagen is divided into fibril-forming collagen (types I, II, III, V, and XI), collagen associated with fibrils (types IX, XII, XIV, XVI, XIX, and XX), and other types of collagen (types IV, VI, VII, VIII, and X). The most abundant are the fibril-forming collagen, comprising $90 \%$ of collagen present in living and are able to form structures with highly organized fibers [9].

Type I collagen is the most studied and most abundant type of collagen. It corresponds to $>90 \%$ of the organic bone mass and is found in tendons, skin, ligaments, and cornea. Type I collagen is the major component that provides rigidity to surrounding structures [9]. All of these features suggest that type I collagen is a good candidate in studies associated with other materials.

In general, studies involving the different types of collagen are extremely important because the differences between their structures and properties may be beneficial in therapeutic applications such as drug delivery systems, growth factor and cell formation anchoring systems, and tissue repair [10].

The interest in conducting research using proteins and silver nanoparticles (AgNPs) extends beyond the field of health and biotechnology. Data on the antimicrobial activity, biocompatibility, and adsorption of AgNPs have been shown in the literature [11-13]. Studies involving medical devices for drug delivery and the interactions between AgNPs and proteins in order to modify or discontinue cellular activities are of paramount importance to the scientific community with applications of interest to the general population [13-15]. Studying the interaction of AgNPs with proteins can be valuable for understanding the stability of nanoparticle systems, the effects of discovery in biological systems, and the development of new pharmaceutical products [16,17].

Alarcon et al. [18] and Cardoso et al. [19] used collagen type I, to stabilize the AgNPs starting from a silver nitrate solution. The authors conducted a study to test the biocompatibility and the antibacterial properties of AgNPs stabilized with collagen. This study was performed biological tests with AgNPcol checking the skin permeation; action against inflammation and flow cytometry. The aim of the current study was to analyze the behavior of the stabilized AgNPs with collagen by assessing cell viability using flow cytometry, permeation front (in vitro), and paw edema induced by carrageenan.

\section{Materials and methods}

\subsection{Synthesis of collagen-based silver nanoparticles (AgNPcol)}

A solution of silver nitrate $\left(\mathrm{AgNO}_{3}\right)$ at a concentration of $108 \mu \mathrm{g} \mathrm{Ag} / \mathrm{ml}$, a solution of collagen type I from rat tail (Santa Cruz Biotechnology, Dallas, TX, USA) at a concentration of $0.1 \mathrm{mg} / \mathrm{ml}$, and a solution of sodium borohydride $\left(\mathrm{NaBH}_{4}\right)$ at a concentration of $3.78 \mathrm{mg} / \mathrm{ml}$ were used to carry out the synthesis of nanoparticles. The collagen was prepared using acetic acid $(10 \mathrm{mg} / \mathrm{ml})$ and $\mathrm{AgNO}_{3}$ and $\mathrm{NaBH}_{4}$ were prepared using ultrapure water at $4{ }^{\circ} \mathrm{C}$. The $\mathrm{AgNO}_{3}$ solution was added to an equal volume of collagen, and the mixture was agitated and homogenized for $10 \mathrm{~min}$. The $\mathrm{NaBH}_{4}$ solution was added later and the solution was homogenized for $10 \mathrm{~min}$. Subsequently, the reaction mixture was centrifuged at $3600 \mathrm{rpm}$ for 15 min (temperature $25^{\circ} \mathrm{C}$ ) and finally separated from the supernatants of the final solution present in the container [19].

\subsection{Structural characterization of AgNPcol}

Powder X-ray diffraction (XRD) was carried out on dried samples in order to determine the phase, percentage of crystallinity, and crystallite size of the silver present in the nanoparticles. The experiment was performed with a diffractometer (Rigaku Ultima IV, Spring, TX, USA) using $\mathrm{CuK} \alpha$ monochromatic radiation in step-scanning mode $\left(0.02^{\circ}\right.$ step) and range of $8-60^{\circ}$ with an exposure time of $5 \mathrm{~s} / \mathrm{step}$. Further investigations were conducted applying the Rietveld refinement, aiming to fit the starting model of the phases, found by searching the previous phase, to the entire powder pattern obtained from the experiment, using the software MAUD [20,21]. The structures were designed using HyperChem and geometrically optimized with Model Building (HyperChemm TM, Professional 8.0.6, Hypercube Inc., Gainesville, FL, USA). Dynamic light scattering (DLS) and zeta potential measurements were conducted on a Zetasizer Nano-ZS (Malvern Instruments, UK) using an acid solution of AgNPcol.

\subsection{Morphological characterization of AgNPcol}

Atomic force microscopy (AFM) analysis was conducted using a TTAFM instrument (AFM Workshop, USA) in vibrating (tapping) mode. Therefore $6 \mu \mathrm{m}$ area scans were conducted after the deposition of $10 \mu \mathrm{l}$ of AgNPcol onto clean mica substrate and the sample was dried at room temperature. Once dry representative images were performed using ACT-20 cantilevers (AppNano - USA) with a resonant frequency of approximately $319 \mathrm{kHz}$. Images were analyzed using Gwyddion software 2.40 .

\subsection{Cell culture}

Chemicals and phosphate buffered saline (PBS) were purchased from Sigma-Aldrich ${ }^{\circledR}$ (St. Louis, MO, USA). Penicillin/streptomycin, fetal bovine serum (FBS), and Dulbecco's modified Eagle medium (DMEM) were purchased from Vitrocell (Campinas, SP, Brazil). Sterile pipettes, plates, and flasks for cell culture were purchased from TPP® (Switzerland). All experiments were done in a clean and sterile atmosphere to eliminate the probability of contamination with endotoxin [22].

The human melanoma cancer (MV3) and murine fibroblast (L929) cell lines were purchased from the cell bank at the Federal University of Rio de Janeiro. Cells were maintained at $37{ }^{\circ} \mathrm{C}$ in a $5 \%$ $\mathrm{CO}_{2}$ /air incubator and cultured in $75-\mathrm{cm}^{2}$ flasks in DMEM supplemented with $10 \%(\mathrm{v} / \mathrm{v}) \mathrm{FBS}$, penicillin/streptomycin $(50 \mathrm{IU} / \mathrm{ml}$ and $50 \mu \mathrm{g} / \mathrm{ml}$, respectively), and $2 \mathrm{mM}$ L-glutamine. The cells were grown to confluence, which was verified by observation under an inverted microscope (Nikon Eclipse Ti®, Japan). The cell viability after exposure to AgNPs was determined using the trypan blue exclusion assay immediately before in vitro assays (data not shown) to verify that the viability was higher than $98 \%$.

\subsection{Apoptosis and necrosis assays by flow cytometry}

Apoptosis and necrosis were analyzed using fluorescein isothiocyanate (FITC)-annexin $\mathrm{V}$ and propidium iodide (PI) staining using a kit (annexin V-FITC apoptosis detection kit, BD ${ }^{\circledR}, \mathrm{USA}$ ) and flow cytometry. Cells were plated in 6-well culture plates for $24 \mathrm{~h}$ to attach. They were then treated with AgNPcol at 4.35, 2.17, 1.08, 0.5, and $0.25 \mu \mathrm{g} \mathrm{Ag} / \mathrm{ml}$, collagen alone at $6.25 \mu \mathrm{g} / \mathrm{ml}$, or $\mathrm{AgNO}_{3}$ alone at $3.37 \mu \mathrm{g} \mathrm{Ag} / \mathrm{ml}$ and $6.25 \mu \mathrm{g}$ $\mathrm{Ag} / \mathrm{ml}$ for $24 \mathrm{~h}$ at $37{ }^{\circ} \mathrm{C}$ in $5 \% \mathrm{CO}_{2}$ before the assays. The untreated cells were considered as negative controls. The annexin V-FITC assay was used to differentiate apoptosis from necrosis induced by AgNPcol after incubation for $24 \mathrm{~h}$. After that, both cells types were harvested, washed twice in cold PBS, and further ressuspended in binding buffer. Next, FITC-labeled annexin $\mathrm{V}$ was added and incubated for $15 \mathrm{~min}$ in the dark at $25{ }^{\circ} \mathrm{C}$. PI was added and incubated for 5 min in the dark. Cells were immediately analyzed by flow cytometry. Ten thousand cells were analyzed as percentages and the data stored. The excitation wavelength was set at $488 \mathrm{~nm}$. Flow cytometry analysis was performed in a FACSCalibur ${ }^{\circledR}$ (Becton Dickinson, CA, USA) with the BD CellQuest 3.3 software. 


\subsection{Analysis by permeation diffusion cell}

For the in vitro study of skin permeation in an animal model, the skin on the back of a pig's ears was initially selected [23,24]. The skin was extracted from the ears, and the epidermis and dermis were maintained by removing the adipose tissue in the region. The test pieces were cut from the pig's ears and packaged in a Franz diffusion cell with a surface diffusion area of $1.77 \mathrm{~cm}^{2}$. They were mounted in five Franz cells, maintained at $37^{\circ} \mathrm{C}$ by using a circulating water bath and stirred at $400 \mathrm{rpm}$. Isotonic phosphate buffer at $\mathrm{pH} 7.4$ was placed in the recipient cell.

After the system was mounted, $200 \mu \mathrm{l}$ of AgNPcol ( $50 \mu \mathrm{g} \mathrm{Ag} / \mathrm{ml})$ was added onto the skin and immediately, the first sample was collected for testing. The samples were collected hourly for $6 \mathrm{~h}$ and placed in test tubes, and every time a sample was taken, it was replaced by an equal amount of isotonic phosphate buffer [25]. Thereafter, the test pieces were removed from the diffusion cells and two procedures were performed. First, the upper skin cells were removed with adhesive tape (tape strips). In total, 15 tape strips were made and were placed in a test tube. In the second procedure, small pieces of skin were cut and put in another test tube. Methanol was added to both vials to remove skin extracts for analysis. These procedures were conducted to check if there was AgNPcol retained in the skin layers.

For the analysis of solutions and subsequent verification of AgNPcol content present in the skin layers or present as a result of diffusion, the receiving cell was assessed by using atomic absorption spectroscopy (Varian AA240FS) at a wavelength of $328.1 \mathrm{~nm}$ with a multi-element lamp (Varian No. 5610108700). The equipment was prepared for silver detection by performing calibration with a sample of AgNPcol at a known concentration. Samples to be tested received an aliquot (10\% by volume) of nitric acid (10\%) to prevent clogging of the equipment piping. The samples were analyzed in a flame atomic absorption system with acetylene gas following the manual's recommendations. The results were expressed in $\mu \mathrm{gg} / \mathrm{cm}^{2}$ with respect to the diffusion area. The same experiment was used to perform $\mathrm{AgNO}_{3}$ permeation for comparison.

\subsection{Paw edema induced by carrageenan}

$\lambda$-Carrageenan was purchased from Sigma-Aldrich ${ }^{\circledR}$. AgNPcol and collagen were the same as those used earlier in this study. Male Swiss mice $(25-30 \mathrm{~g})$ were housed in cages at room temperature controlled at $25 \pm 2{ }^{\circ} \mathrm{C}$ under light-dark cycles of $12 \mathrm{~h}$ each and supplied with food and water ad libitum. All animals were treated in accordance with the Guide for Care and Use of Laboratory Animals [26] during the experiment. The Research Ethics Committee with animals of the Federal University of Piauí approved the experiment, number 038/15.

The paw edema experiment was modified and used as previously described [27]. The animals were randomly divided into 4 groups, and edema was induced by injection of $50 \mu \mathrm{l}$ of a $0.5 \%$ suspension $(\mathrm{w} / \mathrm{v})$ of carrageenan $(500 \mu \mathrm{g} / \mathrm{paw})$ in $0.9 \%$ sterile saline into the aponeurosis plantar right. The AgNPs were topically administered immediately following injection with carrageenan. The following groups were studied: $0.9 \%$ sterile saline (untreated control group I, $n=5$ ); carrageenan ( $500 \mathrm{mg} / \mathrm{paw}$, untreated control group II, $n=5$ ); AgNPcol solutions applied topically ( $50 \mu \mathrm{g} \mathrm{Ag} / \mathrm{ml}$, treatment group I, $n=9$ ); collagen solution applied topically $(0.1 \mathrm{mg} / \mathrm{ml}$, treatment group II, $n=4)$. The volume of the right hind foot was measured with an Ugo Basile plethysmometer7140 at $0,1,2,3,4$, and $5 \mathrm{~h}$ after application of carrageenan. The effect of pre-treatment was calculated as the relative percentage of inhibition of paw volume as compared to that in the saline-treated control edema using the following formula [28]:

\%inhibition of edema $=\frac{(\mathrm{Vt}-\mathrm{Vo}) \text { control }-(\mathrm{Vt}-\mathrm{Vo}) \text { treat }}{(\mathrm{Vt}-\mathrm{Vo}) \mathrm{control}} \times 100$ wherein Vo is the baseline volume and Vt is the final volume measured at the above-mentioned time points.

\subsection{Myeloperoxidase activity}

The extent of accumulation of neutrophils in the paw of the mice was measured by assessing the myeloperoxidase (MPO) activity. In summary, 50-100 $\mathrm{mg}$ of hind paw tissue was homogenized in $1 \mathrm{ml}$ of $0.5 \%$ hexadecyltrimethylammonium bromide for every $50 \mathrm{mg}$ of tissue. The homogenate was centrifuged at $4000 \mathrm{rpm}$ for $15 \mathrm{~min}$ at $4{ }^{\circ} \mathrm{C}$. Then, $10 \mu \mathrm{l}$ of supernatant was collected and the activity of MPO was assessed by measuring the shift in absorbance at $450 \mathrm{~nm}$ using o-dianisidine dihydrochloride with $1 \%$ hydrogen peroxide. MPO activity was reported as units/mg of tissue. One unit of MPO activity is defined as $1 \mu \mathrm{mol}$, which converts hydrogen peroxide to water in $1 \mathrm{~min}$ at $22^{\circ} \mathrm{C}$.

\subsection{Statistical analysis}

All in vitro experiments were analyzed in triplicate and the results were expressed as mean \pm standard deviation of three separate experiments. The results were considered statistically significant when $p<0.05$. Data were evaluated by one-way analysis of variance (ANOVA) followed by post-hoc Tukey's multiple comparison test, using Graph Pad Prism program software version 5.0.

The in vivo results were expressed as mean \pm standard error of the mean for at least four animals per group, and statistical analysis was presented using Kruskal-Wallis with post-hoc de Dunn. Statistical significance was set at $p<0.05$.

\section{Results and discussion}

\subsection{Characterization of AgNPcol}

The crystallinity profile of AgNPcol was obtained by XRD and analyzed by the Rietveld method after normalization based on the amorphous region, which belonged to the collagen phase. The other phases found in the Inorganic Crystal Structure Database (ICSD) searches showed the presence of silver (ICSD 44387) and silver chloride (ICSD 56538). The convergence of the method was determined by the R indices (Rwp, Rexp, and the goodness of fit $\chi^{2}$ ) [29] calculated after each refinement cycle, which include the adjustment of the profiles by the least-square of the parameters for lattice cell, peak broadening, and background. Fig. 1 shows the diffractogram after the completion of the

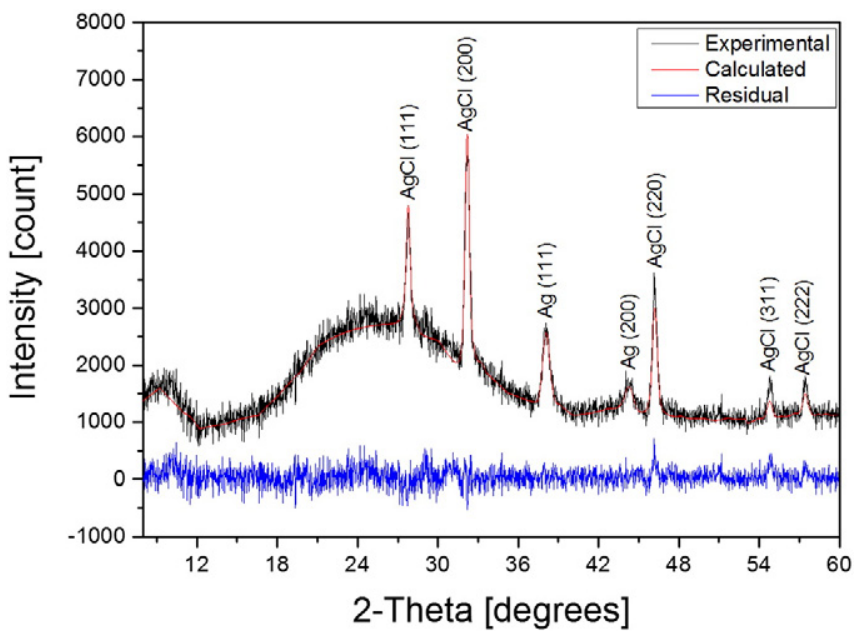

Fig. 1. Rietveld plot of AgNPcol. Experimental data are indicated by a black line, calculated data by a red line, and difference curve by a blue line below. 


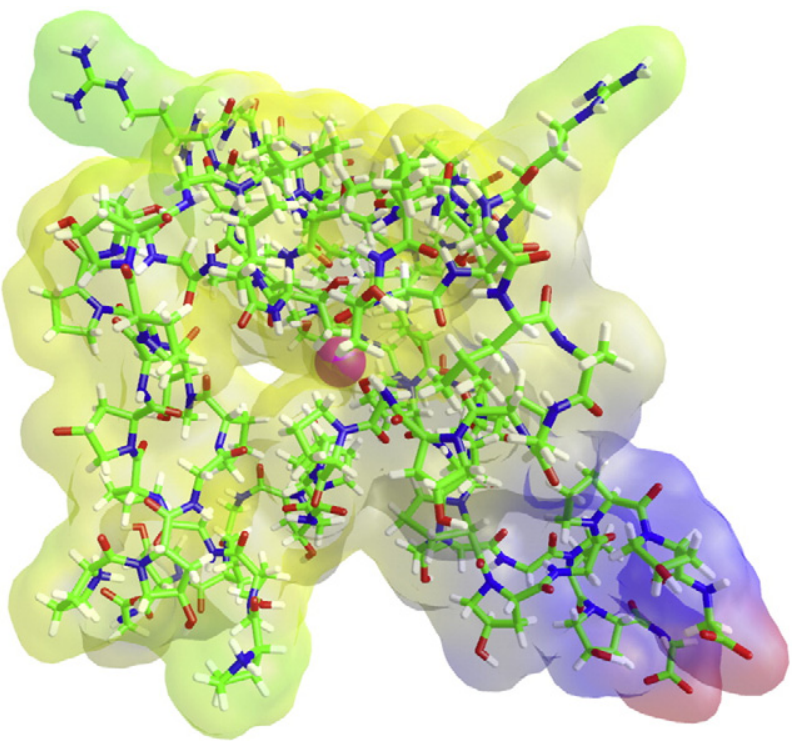

Fig. 2. Schematic model representation of type I collagen fiber constructed through geometric optimization. The red spheres represent silver atom.

refinement, which shows the convergence of the data with a smooth residual curve and low R-values: $\mathrm{R}_{\exp }=0.96508, \mathrm{R}_{\mathrm{wp}}=1.45883$, and goodness of fit $\chi^{2}=1.51161$. The crystal size of the silver phase was computed by the Rietveld method to be $138.78832 \mathrm{~nm}$. The percent crystallinity was calculated as the ratio of crystalline peak area to the total area of the diffractogram and was found to be $12.67667 \%$ crystallite phase. In addition to the pure silver phase in the sample, the $\mathrm{AgCl}$ phase was found. As the synthesis of the nanoparticles does not involve chloride. The presence of chloride occurs only in collagen purification and because of this was the formation of $\mathrm{AgCl}$. However, there were no phases of silver oxide, showing that the metal nanoparticle was better stabilized.

At an acidic $\mathrm{pH}$, the amino acids along the type I collagen molecule are positively charged, imparting the entire collagen molecule a positive charge and making assembly formation around metallic ions feasible. Thus, the results indicated the formation of metallic clusters surrounded by collagen. These clusters aggregated themselves to give rise to the nanoparticles, which was evident if the crystallinity data were analyzed at around 12\% (Fig. 2).

Particle size and distribution were determined by DLS and results showed a particle size of $140.7 \pm 7.8 \mathrm{~nm}$ and a zeta potential of $+20.1 \pm 0.7$. The particle size determined by DLS is in accordance with the crystallite size of the silver phase determined by the Rietveld method, despite the difference in the measurement states. Through these data, we can conclude that the AgNPcol profile does not change with shifts of solid media in liquid, and maintains its cohesive structure. The morphology of AgNPcol can be seen in Fig. 3 in which we can observe spherical nanoparticles.

\subsection{Cytotoxicity assays: apoptosis and necrosis processes by flow cytometry}

As shown in Figs. 4, 5, and 6, early apoptosis, late apoptosis, and necrosis were not induced by AgNPcol in L929 cells when compared with the negative control $(p>0.05)$. The late apoptosis process was significantly triggered in $\mathrm{L}^{2} 9$ cells by $\mathrm{AgNO}_{3}$ alone $(p<0.05)$ (Fig. 4). This result corroborated with that obtained in previous studies [19], which demonstrated that AgNPcol is not cytotoxic.

\subsection{MV3 cancer cells}

After incubation of MV3 cells with AgNPcol for $24 \mathrm{~h}$, cell viability was determined by apoptosis and necrosis assays. As shown in Fig. 7, the cell
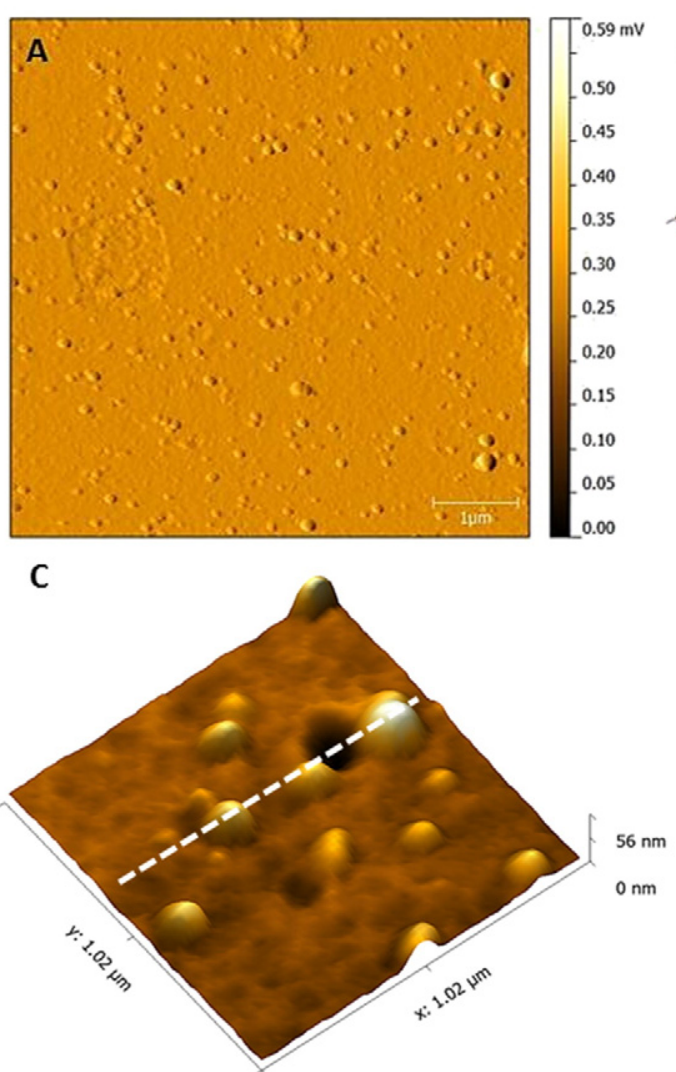

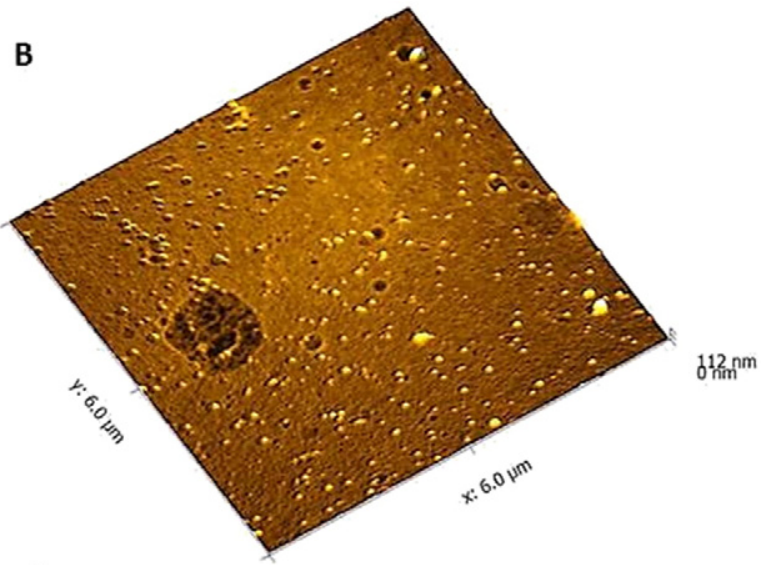

D

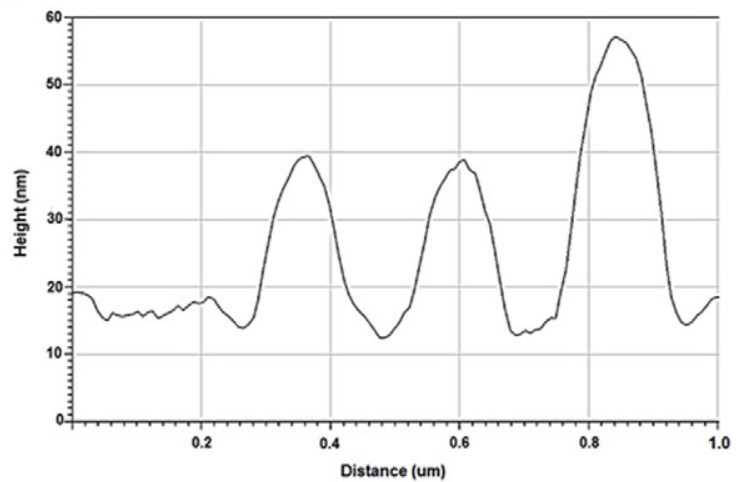

Fig. 3. (A) AFM 2D image AgNPcol; (B) AFM 3D image AgNPcol. ( $6.0 \mu \mathrm{m} \times 6.0 \mu \mathrm{m})$; (C) extended 3D image $(1.02 \mu \mathrm{m} \times 1.02 \mu \mathrm{m})$; (D) profile of AgNPcol. 


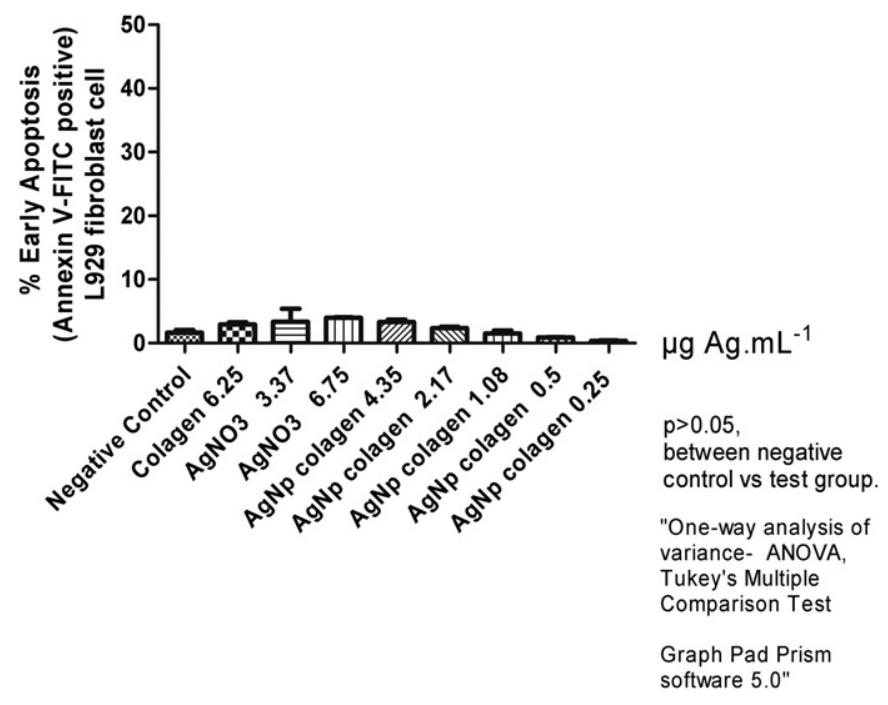

Fig. 4. Effect of AgNPcol on the percentage of early apoptotic cells in L929 fibroblast cells assayed by annexin V-FITC positive/PI negative staining. Data are reported as means \pm standard deviation. *Statistically different from the negative control group (ANOVA, Tukey's multiple comparison test, $p>0.05$ ).

viability decreased significantly compared to that of the negative control $(p<0.05)$, except when treated with $6.25 \mu \mathrm{g} / \mathrm{ml}$ collagen alone. The early and late apoptosis processes were induced by AgNPcol, as shown in Figs. 7 and 8, respectively, compared with the negative control $(p<0.05)$. Necrosis was induced when treated with AgNPcol alone at $4.35 \mu \mathrm{g} \mathrm{Ag} / \mathrm{ml}$ (Fig. 9).

It is important to observe that AgNPcol exhibited enhanced toxicological effects in cancer cells, as shown in early and late apoptosis of MV3 cancer cells (Fig. 7) compared to that of L929 normal cells (Figs. 4 and 5 , respectively).

Several authors showed the efficiency and different mechanisms of AgNPs against cancer cells in previous studies. AgNPs induced oxidative stress in the MDA-MB-321 breast cancer cell line [30]. In A549 human lung carcinoma cells, AgNPs activated intrinsic apoptosis [31], and in T24 bladder carcinoma cells, AgNPs were toxic [32]. However, none of these AgNPs was associated with collagen.

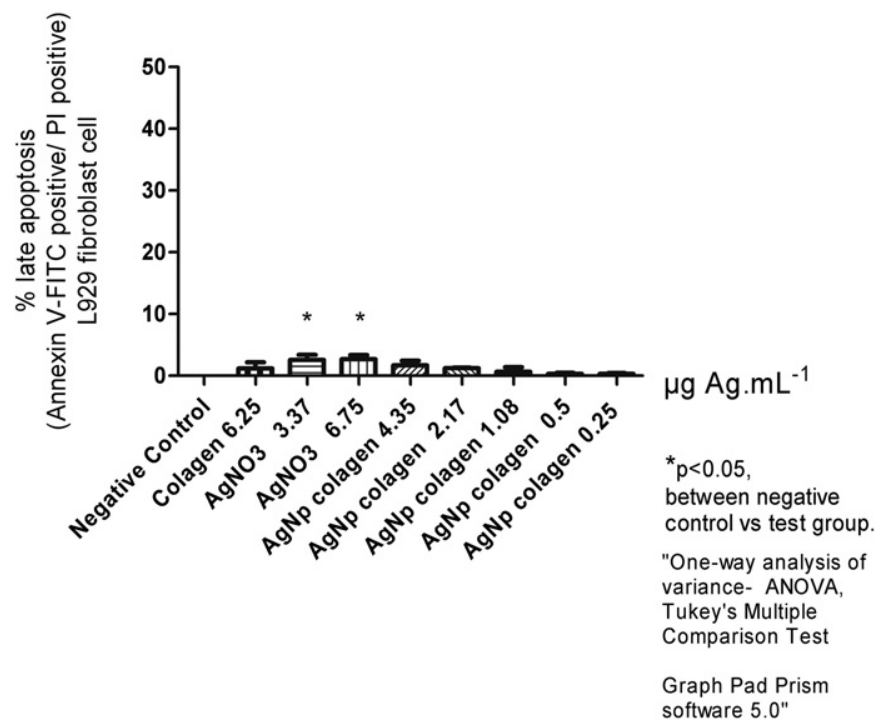

Fig. 5. Effect of AgNPcol on the percentage of late apoptotic/necrotic cells in L929 cells assayed by annexin V/PI double-positive staining. Data are reported as means \pm standard deviation. *Statistically different from the negative control group (ANOVA, Tukey's multiple comparison test, $p<0.05$ ).

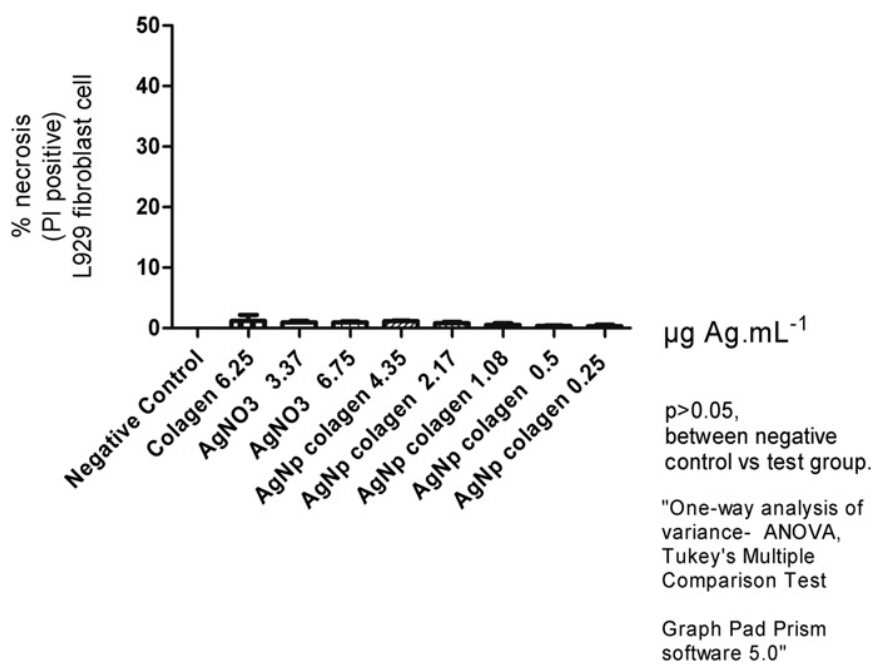

Fig. 6. Effect of AgNPcol on the percentage of necrotic cells in L929 cells assayed by PI positive staining. Data are reported as means \pm standard deviation. *Statistically different from the negative control group (ANOVA, Tukey's multiple comparison test, $p>0.05$ ).

Reactive oxygen species (ROS) generation may induce toxic effects in cells after exposure to nanoparticles $[33,34,35]$. Based on our previous cyto and genotoxicology results [35] and evidences available from literature regarding the toxic mechanisms of AgNps, the ROS production has been documented as the primary mechanisms induced by the nanoparticles [36].

Our previous study shows that AgNps capped with PVA (polyvinylalcohol) induced ROS generation, leading to DNA damage in primary normal human peripheral blood mononuclear cell (PBMC) and in HepG2 human cancer (hepatocarcinoma) cells [35]. This mechanism may induce further apoptosis or necrosis in major extension in cancer cells.

The electrostatic interactions between positively charged nanomaterials and target cancer cells have been described in the literature. Cancer cells usually exhibit a high concentration of anionic phospholipids on their outer leaflet, in comparison to normal cells that exhibit zwitterionic phospholipids [37]. This condition plays an important role in cellular uptake [38] of positively charged nanoparticles in

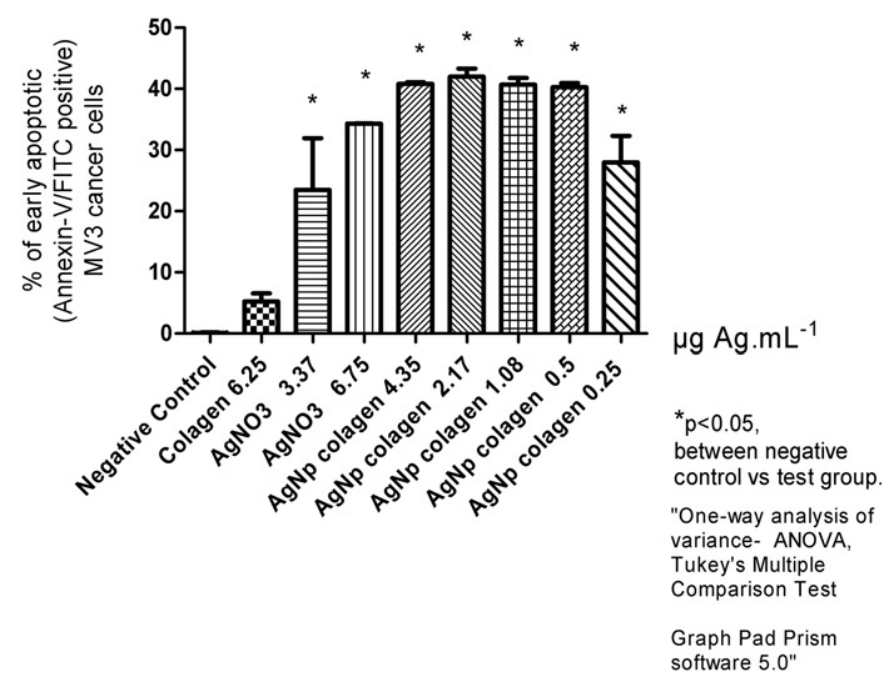

Fig. 7. Effect of AgNPcol on the percentage of early apoptotic cells in MV3 cancer cells assayed by annexin V-FITC positive/PI negative staining. Data are reported as means \pm standard deviation. *Statistically different from the negative control group (ANOVA, Tukey's multiple comparison test, $p<0.05$ ). 


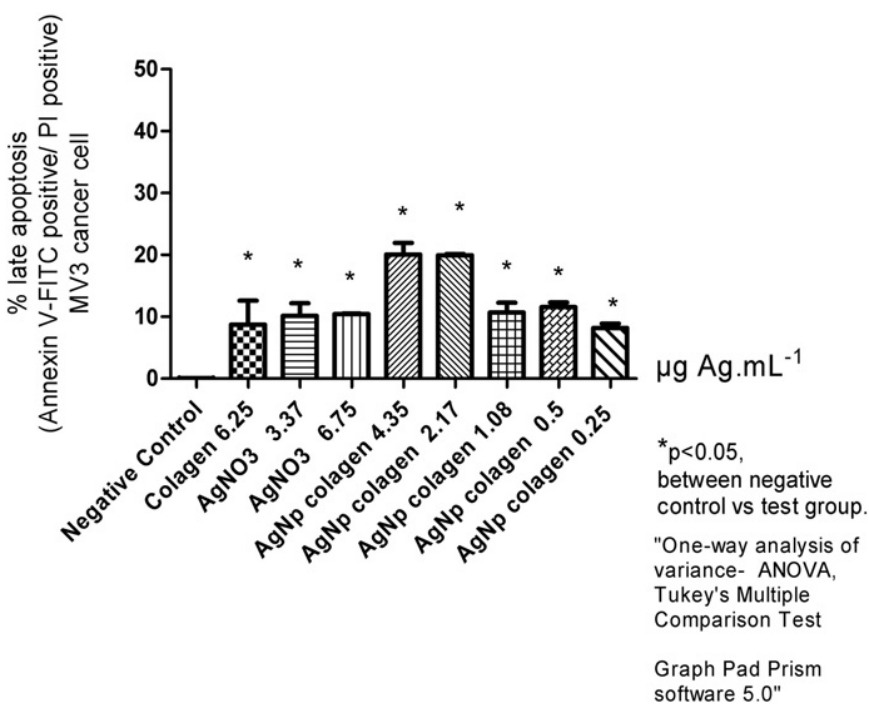

Fig. 8. Effect of AgNPcol on the percentage of late apoptotic/necrotic cells in MV3 cancer cells assayed by annexin V/PI double-positive staining. Data are reported as means \pm standard deviation. *Statistically different from the negative control group (ANOVA, Tukey's multiple comparison test, $p<0.05$ ).

cancer cells, in comparison to normal cells. Since the AgNPcol nanoparticles are positively charged (zeta potential of $+20.1 \mathrm{mV}$ ), we may expect them to be more toxic to cancer cells than to normal cells.

\subsection{Permeation diffusion cell and edema tests in mouse paw}

Analysis of the samples of skin permeation performed using atomic absorption spectroscopy showed diffusion of AgNPcol. The results showed that $0.14 \mu \mathrm{g} \mathrm{Ag} / \mathrm{cm}^{2}$ of AgNPcol underwent diffusion, as it was found in the recipient side of the Franz cell. In the skin, AgNPcol was found to occur at $0.11 \mu \mathrm{g} \mathrm{Ag} / \mathrm{cm}^{2}$. This shows the action potential of AgNPcol in skin layers and in the region below the skin, allowing applications in local injury and trauma models. For $\mathrm{AgNO}_{3}, 0.23 \mu \mathrm{g} \mathrm{Ag} / \mathrm{cm}^{2}$ was retained on the skin and only $0.03 \mu \mathrm{g} \mathrm{Ag} / \mathrm{cm}^{2}$ suffered diffusing. This was probably because the $\mathrm{AgNO}_{3}$ molecule was larger than the nanoparticles, thereby trapping the $\mathrm{AgNO}_{3}$ in the skin [19].

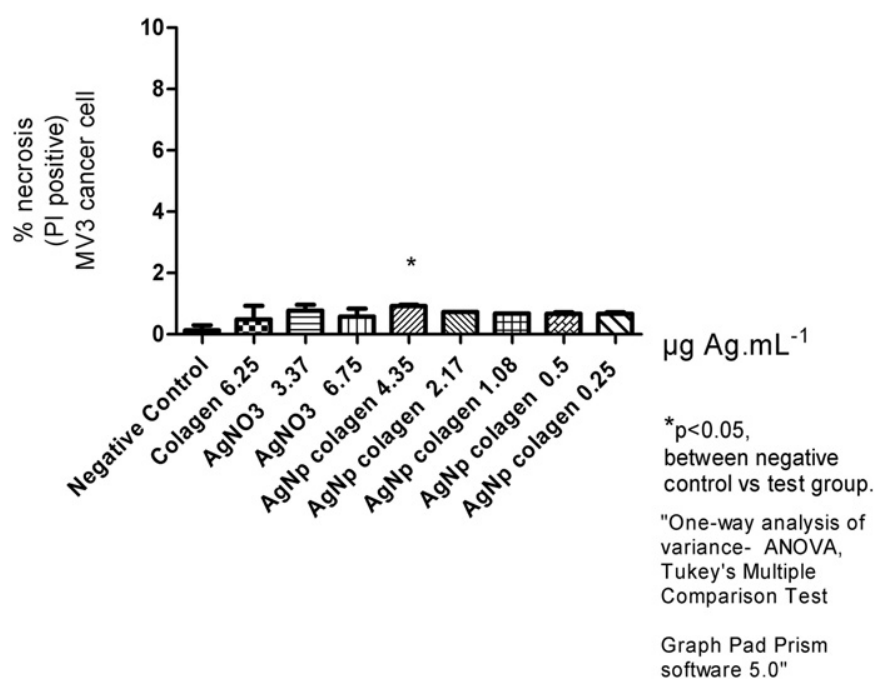

Fig. 9. Effect of AgNPcol on the percentage of necrotic cells in MV3 cancer cells assayed by PI positive staining. Data are reported as means \pm standard deviation. *Statistically different from the negative control group (ANOVA, Tukey's multiple comparison test, $p<0.05$ ).

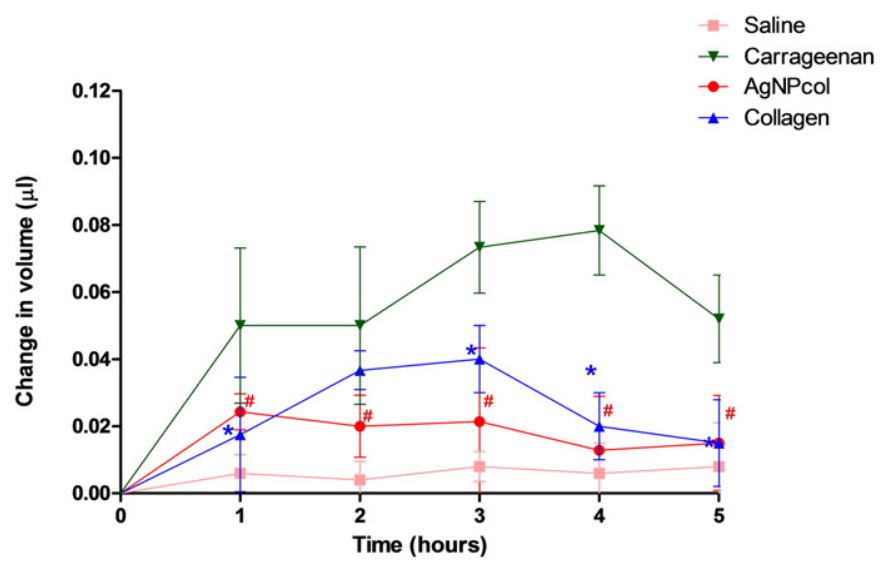

Fig. 10. Effect of AgNPcol and collagen on carrageenan-induced paw edema. Paw edema was induced by carrageenan injection $(500 \mu \mathrm{g}$ per paw $/ 50 \mu \mathrm{l})$ into the plantar right paw. Paw volume was measured 0, 1, 2, 3, 4, and 5 h after carrageenan injection. AgNPcol was administered immediately after the inflammatory stimulus. Values are given as mean \pm SEM $(n \geq 5)$. ${ }^{\#} p<0.05$ compared with AgNPcol plus carrageenan group; ${ }^{*} p<0.05$ compared with collagen plus carrageenan group. Statistical analysis was performed using Kruskal-Wallis test with post-hoc de Dunn.

In the latter part of the skin permeation study, edema tests were performed in mouse paw. In this experiment, the carrageenan stimulated the formation of edema in animal paws, as described in the method followed by Winter [27], enabling the application of the solutions to be tested (Fig. 10). The peak was observed in the fourth hour of the study and subsequently, the edema began to decrease spontaneously.

Collagen and AgNPcol were applied topically to treat edema for $5 \mathrm{~h}$. In this experiment, the formation of edema in animals in which collagen was applied was lower than that in the carrageenan group. The collagen group peaked at the third hour, and edema diminished thereafter. In the group that was treated with AgNPcol, maximum swelling was observed in the first hour and swelling did not increase with the passage of time. Moreover, edema formation was decreased as compared with that in the carrageenan and collagen groups, demonstrating the effectiveness of AgNPcol in preventing edema formation (Fig. 10).

At the end of the animal study, the accumulation of neutrophils in the paw of animals (UMPO) was evaluated. The carrageenan inflammation was found to stimulate the site of application with a large presence

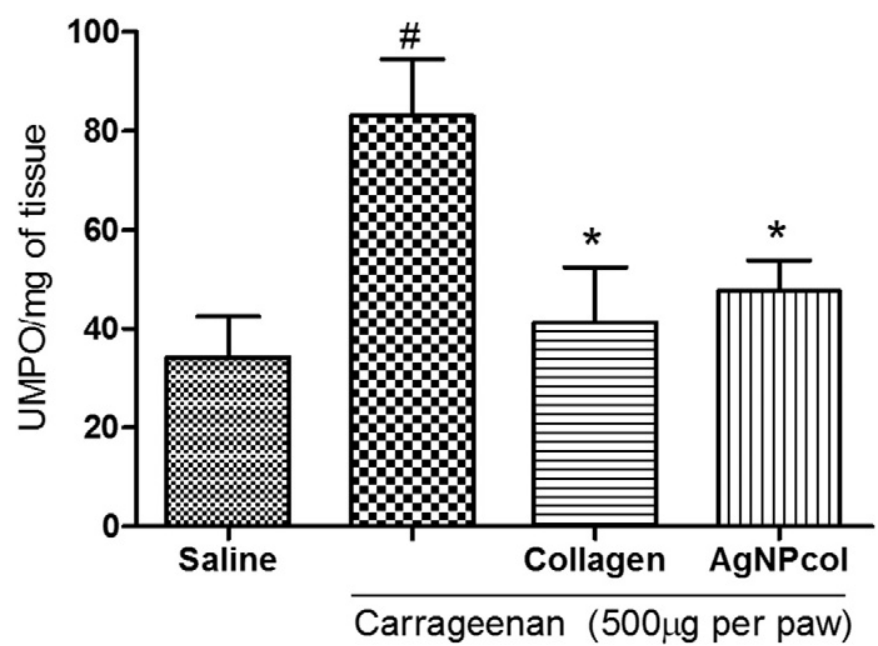

Fig. 11. Effect of AgNPcol and collagen on carrageenan-induced myeloperoxidase activity in paw tissue. Saline or carrageenan ( $500 \mu \mathrm{l}$ per paw) was injected into the plantar surface of mice immediately after animals had been treated with AgNPcol or collagen. Myeloperoxidase (MPO) activity was detected in the paw tissue after $5 \mathrm{~h}$. The results are expressed as the mean \pm SEM MPO units (UMPO)/mg of tissue. ${ }^{*} p<0.05$ compared with carrageenan group; ${ }^{\#} p<0.05$ compared with saline. Statistical analysis was performed using Kruskal-Wallis test with post-hoc de Dunn. 
of neutrophils in the region (Fig. 11). By analyzing the action of collagen and AgNPcol from neutrophil infiltration, it was observed that the actions were similar with no significant differences between them. This is because the action against inflammation was mediated by collagen $[39,40]$ and thus, similar actions were expected. The accumulation of neutrophils in the animals' paws was investigated $5 \mathrm{~h}$ after the analysis of volume (edema); thus, the collagen molecules were able to penetrate the skin of the animal, causing an expected effect similar to that of AgNPcol. It may be noted that both collagen and AgNPcol decreased the amount of neutrophils in the region; however, AgNPcol had a significant proportion in the second hour after application, as seen in Fig. 11.

\section{Conclusions}

The innovation of this study is the submission AgNPcol in biological tests. The silver nanoparticles stabilized with collagen (AgNPcol) failed to induce early apoptosis, late apoptosis, and necrosis; however, they exhibited enhanced toxicological effects in cancer cells (MV3) in comparison with normal cells (L929). The results of the cell skin permeation assay displayed the ability of AgNPcol to diffuse through skin layers and to the region below the skin, allowing applications in local injury. When used in an edema test in the paws of mice, these nanoparticles were found to be effective in preventing edema formation. These results suggest the healing potential of AgNPcol in skin injuries, owing to its capacity of penetration in tissues and its ability to prevent one of the classical signs of inflammation without harming one's own tissues. AgNPcol can be used as a viable alternative to improve the repair process, thereby making it necessary to study this perspective further.

\section{Conflict of interest}

The authors declare no conflict of interest.

\section{Acknowledgments}

The authors would like to thank CAPES/PNPD (Brazil) (2952/2010/ 23038007902/2010-25), NanoBioMed Brazil Network (CAPES), and CNPq (Nanotoxicology) for financial support. Ana Carolina Mafud is grateful to FAPESP (2014/02282-6). Larissa Fernandes Batista is grateful to FAPESP (2015/10267-0). Yvonne Primerano Mascarenhas is grateful to CNPq (Grant 302674/2010-1).

\section{References}

[1] N.C. Avery, A.J. Bailey, V.H. Barocas, A.A. Biewener, R.D. Blank, A.L. Boskey, Collagen: Structure and Mechanics, first ed. Springer Science \& Business Media, New York, 2008.

[2] C. Dornelles, S.S. da Costa, M. Laux, R. Weber, Estudo comparativo da dissolução de três diferentes marcas de colágeno utilizadas em técnicas cirúrgicas otológicas, Rev. Brás. Otorrinolaringol. 69 (2003) 744-751.

[3] E. Tonhi, A.M.G. Plepis, Obtenção e caracterização de blendas colágeno-quitosana, Qim. nova. 25 (2002) 943-948.

[4] L. Yang, L.M. Zhang, Chemical structural and chain conformational characterization of some bioactive polysaccharides isolated from natural sources, Carbohydr. Polym. 76 (2009) 349-361.

[5] M. De Paula, G. Goissis, V.C.A. Martins, Compósitos de colágeno aniônico: ramsana como géis injetáveis para correções plásticas: preparação, caracterização e propriedades reológicas, Rev. Brás. Eng. Biomed. 18 (2002) 7-16.

[6] C.H. Lee, A. Singla, Y. Lee, Biomedical applications of collagen, Int. J. Pharm. 221 (2001) 1-22.

[7] W. Friess, Collagen - biomaterial for drug delivery, Eur. J. Pharm. Biopharm. 45 (1998) 113-136.

[8] H.C. Goo, Y.S. Hwang, Y.R. Choi, H.N. Cho, H. Suh, Development of collagenase-resistant collagen and its interaction with adult human dermal fibroblasts, Biomaterials 24 (2003) 5099-5113.

[9] K. Gelse, E. Poschl, T. Aigner, Collagens-structure, function, and biosynthesis, Adv. Drug Deliv. Rev. 55 (2003) 1531-1546.

[10] D. Schuppan, M. Schmid, R. Somasundaram, R. Ackermann, M. Ruehl, T. Nakamura, E.O. Riecken, Collagens in the liver extracellular matrix bind hepatocyte growth factor, Gastroenterology 114 (1998) 139-152.
[11] A. Ravindran, A. Singh, A.M. Raichur, N. Chandrasekaran, A. Mukherjee, Studies on interaction of colloidal Ag nanoparticles with bovine serum albumin (BSA), Colloids Surf. B. Biointerfaces 76 (2010) 32-37.

[12] X. Zhao, R. Liu, Y. Teng, X. Liu, The interaction between $\mathrm{Ag}^{+}$and bovine serum albumin: a spectroscopic investigation, Sci. Total Environ. 409 (2011) 892-897.

[13] C. Bhan, C. Mandlewala, A. Gebregeorgis, D. Raghavan, Adsorption-desorption study of BSA conjugated silver nanoparticles (Ag/BSA NPs) on collagen immobilized substrates, Langmuir 28 (2012) 17043-17052.

[14] I. Brigger, C. Dubernet, P. Couvreur, Nanoparticles in cancer therapy and diagnosis, Adv. Drug Deliv. Rev. 54 (2002) 631-651.

[15] I.L. Medintz, H.T. Uyeda, E.R. Goldman, H. Mattoussi, Quantum dot bioconjugates for imaging, labelling and sensing, Nat. Mater. 4 (2005) 435-446.

[16] S. Kittler, C. Greulich, J.S. Gebauer, J. Diendorf, L. Treuel, L. Ruiz, et al., The influence of proteins on the dispersibility and cell-biological activity of silver nanoparticles, J. Mater. Chem. 20 (2010) 512-518.

[17] N.N. Mamedova, N.A. Kotov, A.L. Rogach, J. Studer, Albumin-CdTe nanoparticle bioconjugates: preparation, structure, and interunit energy transfer with antenna effect, Nano Lett. 1 (2001) 281-286.

[18] E.I. Alarcon, K. Udekwu, M. Skog, N.L. Pacioni, K.G. Stamplecoskie, M. González-Béjar, et al., The biocompatibility and antibacterial properties of collagen-stabilized, photochemically prepared silver nanoparticles, Biomaterials 33 (2012) 4947-4956.

[19] V.S. Cardoso, P.V. Quelemes, A. Amorin, F.L. Primo, G.G. Gobo, A.C. Tedesco, et al., Collagen-based silver nanoparticles for biological applications: synthesis and characterization, J. Nanobiotechnol. 12 (2014) 12-36.

[20] L. Lutterotti, M. Bortolotti, G. Ischia, I. Lonardelli, H.R. Wenk, Rietveld texture analysis from diffraction images, Z. Kristallogr. Suppl. 26 (2007) 125-130.

[21] L. Lutterotti, S. Matthies, H.-R. Wenk, A.S. Schultz, J.W. Richardson Jr., Combined texture and structure analysis of deformed limestone from time-of-flight neutron diffraction spectra, J. Appl. Phys. 81 (1997) 594-600.

[22] H. Vallhov, J. Qin, S.M. Johansson, N. Ahlborg, M.A. Muhammed, A. Scheynius, S. Gabrielsson, The importance of an endotoxin-free environment during the production of nanoparticles used in medical applications, Nano Lett. 6 (2006) 1682-1686.

[23] F.S. de Rosa, A.C. Tedesco, R.F. Lopez, M.B. Pierre, N. Lange, J.M. Marchetti, et al., In vitro skin permeation and retention of 5-aminolevulinic acid ester derivatives for photodynamic therapy, J. Control. Release 89 (2003) 261-269.

[24] L.A. Utracki, Polymeric nanocomposites: compounding and performance, J. Nanosci. Nanotechnol. 8 (2008) 1582-1596.

[25] Guidance for Industry, Extended Release Oral Dosage Forms: Development, Evaluation, and Application of In Vitro/In Vivo Correlations, Food and Drug Administration, Rockville, 1997.

[26] Guide for the Care and Use of Laboratory Animals, National Academies Press (US) Eighth Edition, 2011.

[27] C.A. Winter, E.A. Risley, G.W. Nuss, Carrageenan-induced edema in hind paw of the rat as an assay for anti-inflammatory drugs, Proc. Soc. Exp. Biol. Med. 111 (1962) 544-547.

[28] L.S. Chaves, L.A. Nicolau, R.O. Silva, F.C. Barros, A.L. Freitas, K.S. Aragao, Anti-inflammatory and anti-nociceptive effects in mice of a sulfated polysaccharide fraction extracted from the marine red algae Gracilaria caudata, Immunopharmacol. Immunotoxicol. 35 (2013) 93-100.

[29] L.B. McCusker, R.B. Von Dreele, D.E. Cox, D. Louer, P. Scardi, Rietveld refinement guidelines, J. Appl. Crystallogr. 32 (1999) 36-50.

[30] S. Gurunathan, J.W. Han, V. Eppakayala, M. Jeyaraj, J.H. Kim, Cytotoxicity of biologically synthesized silver nanoparticles in MDA-MB-231 human breast cancer cells, Biomed. Res. Int. 1-10 (2013).

[31] R. Govender, A. Phulukdaree, R.M. Gengan, K. Anand, A.A. Chuturgoon, Silver nanoparticles of Albizia adianthifolia: the induction of apoptosis in human lung carcinoma cell line, J. Nanobiotechnol. 11-5 (2013).

[32] S. Castiglioni, A. Cazzaniga, C. Perrotta, J.A. Maier, Silver nanoparticles-induced cytotoxicity requires ERK activation in human bladder carcinoma cells, Toxicol. Lett. 237 (2015) 237-243.

[33] F. Marano, S. Hussain, F. Rodrigues-Lima, A. Baeza-Squiban, S. Boland, Nanoparticles: molecular targets and cellsignalling, Arch. Toxicol. 85 (2011) 733-741.

[34] I.M. Paino, V.S. Marangoni, R.C. Oliveira, L.M. Antunes, V. Zucolotto, Cyto and genotoxicity of gold nanoparticles in human hepatocellular carcinoma and peripheral blood mononuclear cells, Toxicol. Lett. 30 (2012) 119-125.

[35] I.M. Paino, V.Zucolotto, Poly(vinyl alcohol)-coated silver nanoparticles:activation of neutrophils and nanotoxicology effects in human hepatocarcinoma and mononuclear cells, Environ. Toxicol. Pharmacol. 39 (2015) 614-621.

[36] A. Nel, T. Xia, L. Madler, N. Li, Toxic potential of materials at the nanolevel, Science 311 (2016) 622-627.

[37] N. Papo, M. Shahar, L. Eisenbach, Y. Shai, A novel lytic peptide composed of DL-amino acids selectively kills cancer cells in culture and in mice, J. Biol. Chem. 278 (2003) 21018-21023.

[38] M. Ohgaki, T. Kizuki, M. Katsura, K. Yamashita, Manipulation of selective cell adhesion and growth by surface charges of electrically polarized hydroxyapatite, J. Biomed. Mater. Res. 57 (2001) 366-373.

[39] J. Kajahn, S. Franz, E. Rueckert, I. Forstreuter, V. Hintze, S. Moeller, J.C. Simon, Artificial extracellular matrices composed of collagen I and high sulfated hyaluronan modulate monocyte to macrophage differentiation under conditions of sterile inflammation, Biomaterials 2 (2012) 226-236.

[40] S. Chattopadhyay, R.T. Raines, Review collagen-based biomaterials for wound healing, Biopolymers 101 (2014) 821-833. 